\title{
Numerical and Field Investigation of the Impacts of the Bank Protection Projects on the Fluvial Hydrodynamics (Case Study: Ghezel Ozan River)
}

\author{
Alireza Mojtahedi and Aida Bagheri Basmenji
}

\begin{abstract}
River training refers to the operations which are optimally used in length or width of the river, and provides significant objectives. Achachi Village is one of the most important rural areas of the Mianeh City in Iran, and GhezelOzan River runs adjacent to it and makes its lands more fertile. On the other hand, the arterial borders of the river cause a lot of damages in the area. Therefore, an embankment dike and a couple of fully-stone groynes were constructed to protect the agricultural lands; however, some parts of those structures were destroyed because of flood, and they gradually lost their efficiency. The second phase of Ghezel-Ozan River training studies is done by Water Research Institute belonging ministry of energy. Moreover, the area is modeled by HEC-RAS. The properties, such as average velocity and water depth in the river, can be evaluated by one-dimensional models. However, using two-dimensional models is vital for the modeling the vortex formation between the groynes, determination of optimum distance between them, and the application of the structures. In this study, numerical modeling of the hydraulic phenomena is computed by MIKE21-FM which is one of the most powerful software in the world. Consequently, the groynes impact on Achachi River is investigated in various cross sections, and also vortex formation and stream velocity around them are analyzed.
\end{abstract}

Index Terms-Computational fluid dynamics, finite difference, Groyne, MIKE by DHI software.

\section{INTRODUCTION}

River training refers to total operations that are performed along the length or width of the river to optimize the use and to meet certain goals, such as flood control, erosion and sediment control, guiding flow toward one specific direction, creating spaces for recreation and tourism, and providing the possibility of shipping. Among these goals, flood and erosion control are more discussed for river training [1]. River bank stabilization methods, in terms of implementation methods, are classified as two main types of direct and indirect protection methods. In the indirect protection method, all protection operations are carried out directly on the river bank. In other words, by adopting special measures, bank resistance is increased against erosion and degradation.

Structures that are used in the indirect method of protection are structures parallel to the flow, reverse or transverse structures, and conduct structures. The longitudinal levee as the structure parallel to flow and the

Manuscript received October 17, 2016; revised March 3, 2017.

Alireza Mojtahedi and Aida Bagheri Basmenji are with Department of Civil Engineering, University of Tabriz, Iran (e-mail: Mojtahedi@tabrizu.ac.ir, ayda.bagheri@hotmail.com). groynes as the transverse structures are considered the most common river training structures.

Groynes are constructed in different shapes, length, spacing with each other, and they join to the longitudinal dike with different orientation. The effect of a group of groynes to the flow and the river system is found to be quite different from that of a single groyne [2]. As Yossef mentioned in his literature review [3], Klingeman [4] according to a model test for groynes located along a river bend, describes 6 types of vortex systems, which can form between groynes (Fig. 1).
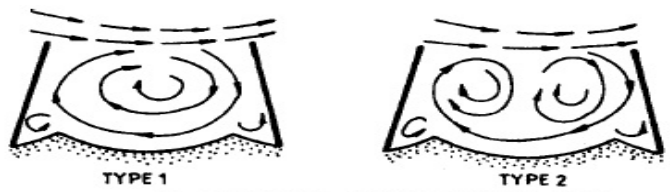

MAIN CURPENT DEFIECTED OUTSIDE GROYNE FIELD.
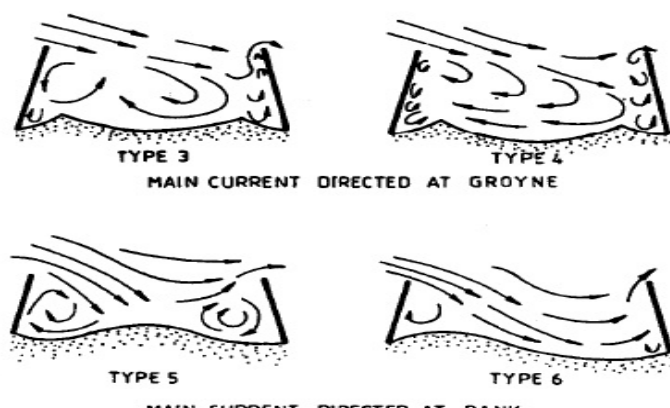

Fig. 1. Types of flow pattern in groyne-field, source: Przedwojski et al (1995) [5].

In type one, a single eddy forms in the groyne's field, which diverts the main flow outside the field. This eddy withholds the main flow from coming inside the area between the groynes. Consequently, this pattern is appropriate for navigation purposes where a continuous deep channel is maintained along the face of the groyne field. In type two, a second vortex appears too, but the flow is enable to enter the groyne-field. As the spacing between two groynes increases, the flow pattern changes. In type five, the two eddies in the corners, provide some protection for the bank. Ultimately, in type six, the circulation pattern which was providing the protection to the bank loses its function and the current directly attacks the bank.

In many studies, characteristics of the flow around different types of groynes have been simulated [6]. Furthermore, there are several experimental studies about flow pattern in the field around different types of groynes [7]-[10].

River studies and the studies of flow phenomena in natural and existing conditions, and in river modifying and training conditions are very complex, time-consuming and 
costly. Thus, the initial plan was prepared using the mathematical model in the form of a physical model of the river. Then by calibration and validation of the function of the physical model and its compliance degree with the mathematical model, other options will be assessed using the mathematical model. Finally, the results of modeling will be extended to the river. In general, the importance of knowing flow characteristics (speeds as a quantity vector and their corresponding depths) beside the hydraulic structures causes the necessity of using mathematical models to design them more accurate.

Features such as average speed and water depth in the river path can be acquired using the one-dimensional models such as HEC-RAS model. One-dimensional models are set up fairly easily, and they can be calibrated quickly. In previous studies, there are comprehensive reviews of onedimensional models together with their applications and numerical solution methods [11]-[13]. The results of these models are used to study the effect of the narrowing of the cross-section caused by dike construction, and the extraction of water level values consistent with those conditions. To determine the distance between the dikes, especially in the arches place, one-dimensional models are not useful, necessitating two-dimensional models to be used. To ensure the formation of eddies between dikes and to determine the optimal distance and layout of used structures, employing a two-dimensional mathematical model of flow is inevitable. Extracting information such as rotational flow rate between dikes, the velocity of flow hitting to the beach, and the rate of flow in front toe (approximately) are several cases that can be achieved in two-dimensional models. MIKE-21 twodimensional model is suitable to simulate the system of floodplain rivers, lakes and beaches, as well as dredging of rivers, especially in the river delta. In addition, it may be helpful in investigating that how the dredging of rivers and estuaries are appropriate to the particular area. In this model, the two-dimensional equations, such as Navier-Stokes equations have been used so that the effects of friction and flow resistance are also considered, in addition to the transverse velocity and turbulence. In two-dimensional models of the horizon level (average depth), the velocity distribution and the acceleration in vertical direction are ignored. Therefore, the secondary effects of erosion snails are ignored in the bed and walls. However, they have a better compatibility for the simulation of flow in the spiral and floodplain rivers (with compound sections).

In this study, the numerical model of MIKE21- FM, which is one of the strongest numerical models for numerical hydrodynamic modeling worldwide, has been used. This model is a dynamic modeling system based on irregular meshing that is generally used in coastal areas, estuaries and rivers.

\section{CASE STUDY}

Ghezel-Ozan River with 5000 cubic kilometers basin is one of the significant rivers in Iran. Training project of Ghezel-Ozan River is in Achachi area of East Azarbaijan Province. Achachi is a rural area which is 10 kilometers far from southeast of Mianeh city. It is of importance since 3.5 kilometers of the Ghezel-Ozan River includes this area. The map of the area is presented in Fig. 2.

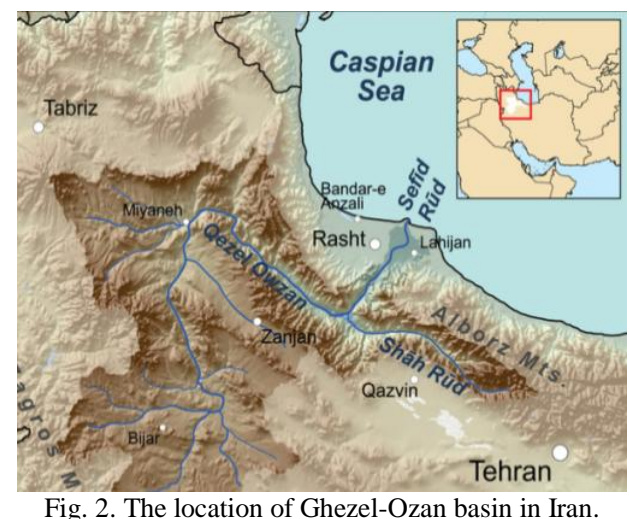

Based on final studies of Ghezel-Ozan River, the domain of the case study is between Poldokhtar and Estour hydrometric station, and its location is about 5 kilometers far from Poldokhtar downstream. The statistics related to Poldokhtar hydrometric station is acquired to investigate the flood in the area. The design base for 25 years of the flood return period in Achachi area equals to 1238 cubic meters. Based on previous studies, roughness coefficient values in different cross sections are evaluated by SCS method, and the mean roughness coefficient equals to 0.031 for this case study. Due to sensitive area of Ghezel-Ozan River, the groynes are totally constructed by stones, and they join longitudinal embankment within the right angle. In addition, groynes' heads are circular to avoid scouring. The length of the groynes is assumed to be 35 to 50 meters, because the river width gets 270 to 350 meters after river training. Also, the crest width is 4 meters and the slope is $1 / 1: 5$ for each groyne. The distance between groynes is assumed twice their length, because the river route is almost straight [14].

\section{MODELING APPROACH}

MIKE 21 is $2 \mathrm{D}$ (depth averaged) process-based numerical modeling software, and it includes different modules which focus on specific processes (hydrodynamics, waves, sediment transport, morphological changes, and water quality). Modules can be coupled to interact with each other.

MIKE $21 \mathrm{HD}$ FM is a flexible mesh flow model that is used for simulating unsteady hydrodynamics using a $2 \mathrm{D}$ (depth averaged) formulation [15].

\section{A. Governing Equations}

The local continuity equation is written as:

$$
\frac{\partial u}{\partial x}+\frac{\partial v}{\partial y}+\frac{\partial w}{\partial z}=\mathrm{S}
$$

The two horizontal momentum equations for the $\mathrm{x}-$ and $\mathrm{y}$ component, respectively:

$$
\begin{gathered}
\frac{\partial u}{\partial t}+\frac{\partial u^{2}}{\partial x}+\frac{\partial u v}{\partial y}+\frac{\partial w u}{\partial z}=\mathrm{fv}-\mathrm{g} \frac{\partial \eta}{\partial x}-\frac{1}{\rho_{0}} \frac{\partial p_{a}}{\partial x}-\frac{g}{\rho_{0}} \int_{z}^{\eta} \frac{\partial \rho}{\partial x} d z \\
+F_{u}+\frac{\partial}{\partial z}\left(v_{t} \frac{\partial u}{\partial z}\right)+u_{S} \mathrm{~S}
\end{gathered}
$$




$$
\begin{gathered}
\frac{\partial v}{\partial t}+\frac{\partial v^{2}}{\partial y}+\frac{\partial u v}{\partial x}+\frac{\partial w u}{\partial z}=\mathrm{fu}-\mathrm{g} \frac{\partial \eta}{\partial y}-\frac{1}{\rho_{0}} \frac{\partial p_{a}}{\partial y}-\frac{g}{\rho_{0}} \int_{z}^{\eta} \frac{\partial \rho}{\partial y} d z \\
+F_{v}+\frac{\partial}{\partial z}\left(v_{t} \frac{\partial v}{\partial z}\right)+v_{s} \mathrm{~S}
\end{gathered}
$$

Hydraulic modeling of continuous fluid with NavierStokes equations requires finding approximate solution at discrete points in the space-time domain. Discretization means Determination of points in the space-time domain, which necessitates selection of node spacing and time step. Most commercial software package express derivatives and integrals by discrete functions called finite difference schemes [9].

MIKE21 uses implicit finite difference method to solve the governing equations on a staggered grid too. The numerical scheme is called ADI (Alternating Direction Implicit). ADI has been widely used because of its wide range of stability and ability to form a balance between computational cost and precision.

\section{B. Model Description}

The basic requirements of input data to run the model are related to spatial and temporal parameters such as computational mesh, bathymetry, simulation length and overall time step. During the mesh generation process, bathymetric values were extracted from the AutoCAD plan of the area by Global Mapper software, which provided data compatible with MIKE. Mesh independency is essential for obtaining reliable results from the models. In this investigation, the largest mesh which is smaller than that has no significant changes in essential parameters and current speed, has been chosen.

Current fields are simulated using grid with flexible meshes, covering Ghezel-Ozan River and a part of area around it (Fig. 3).
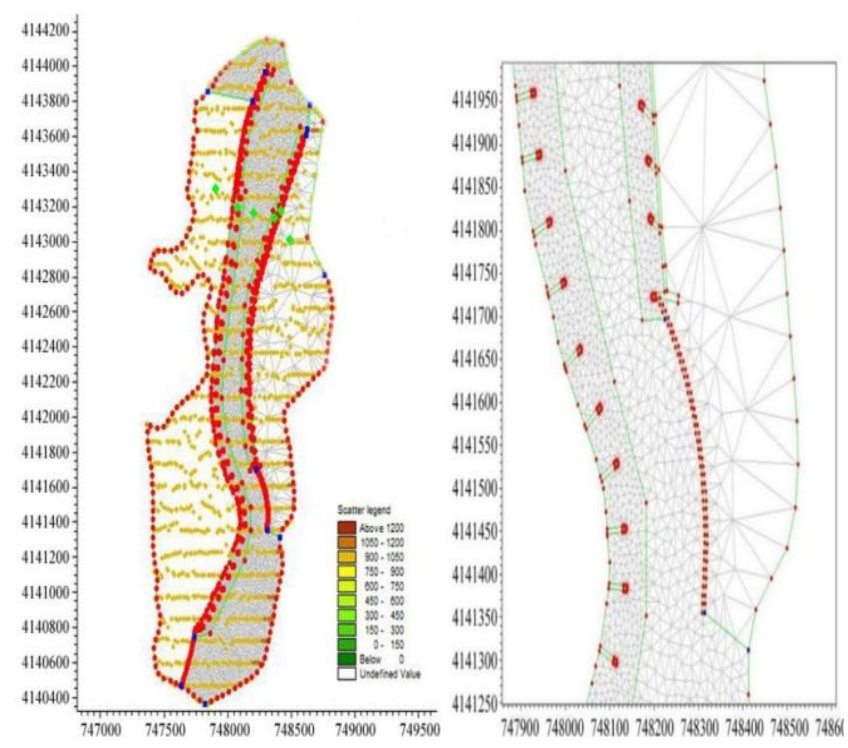

Fig. 3. Computational domain for MIKE2 FM. Ghezel-Ozan River and its surround area, and Created mesh around groyns.

\section{DATA ANALIZING}

Stream velocity, depth, and water surface elevations in each given cross section are analyzed by MIKE software and output data can be achieved in Line Series. The coordinate of the first and the last points on the section must be input to the software, and some points must be specified on that section. In the second phase of Ghezel-Ozen River training in Achachi Area, which is conducted by Water Research Institute belonging ministry of energy, the domain was modeled by HEC-RAS. 25 cross sections in the length of about 3.3 kilometers were chosen for inputing data to the model. Moreover, the hydraulic parameters, such as average velocity were computed in these cross sections. The given cross sections are presented in Fig. 4.

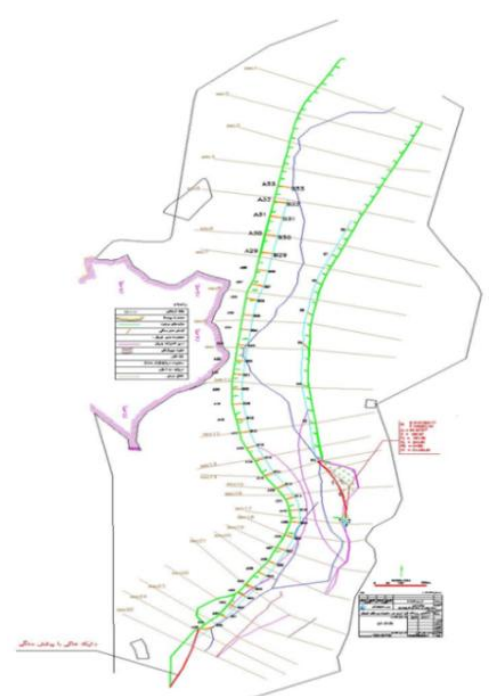

Fig. 4. AutoCAD Plan of the domain and given cross sections on it.

10 cross sections out of 25 mentioned cross sections are specified, and average velocity values before and after river training were evaluated by MIKE in 10 point on those cross sections. For example, the output data of MIKE on third cross section before river training is shown in Table I and Fig. 5.

TABLE I: AVERAge Velocity VAlues IN 10 PoINTS ON THIRD CROSS SECTION BEFORE RIVER TRAINING (THE FIRST ROW SHOWS NUMBER OF POINTS ON THE $3^{\text {RD }}$ CROSS SECTION, AND SECOND ROW PRESENTS THE V

\begin{tabular}{|c|c|c|c|c|c|c|c|c|c|}
\hline 0 & 1 & 1 & 3 & 4 & 5 & 6 & 1 & 8 & 9 \\
\hline
\end{tabular}
VALUES (M/S))

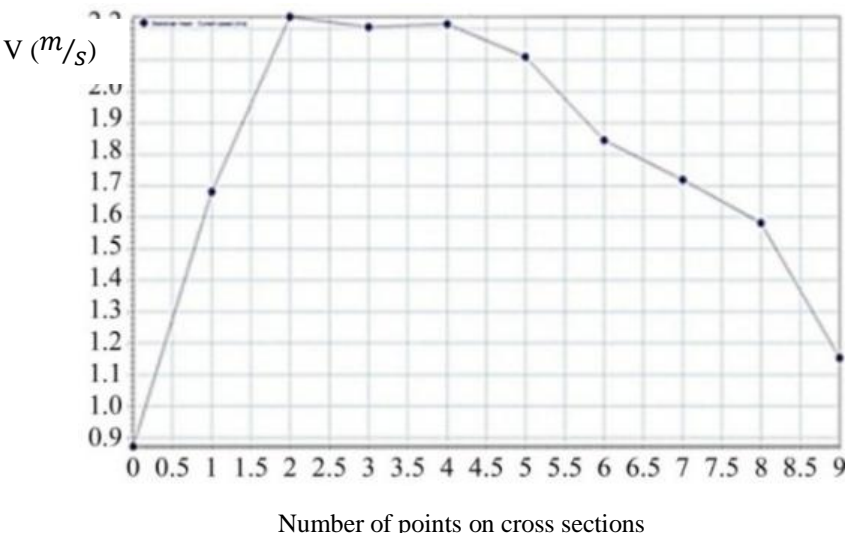

Fig. 5. Average velocity values in 10 points on third cross section before river training.

Furthermore, these values after river training are presented in Table $\Pi$ and Fig. 6. 
TABLE П: AVERAge Velocity VALUES IN 10 POINTS ON THIRD CROSS SECTION AFTER RIVER TRAINING (THE FIRST ROW SHOWS NUMBER OF POINTS ON THE $3^{\text {RD }}$ CROSS SECTION, AND SECOND ROW SHOWS THE V VALUES $(\mathrm{M} / \mathrm{S}))$

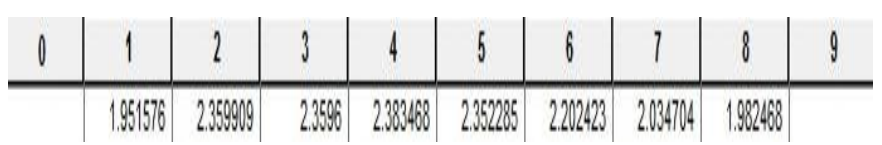

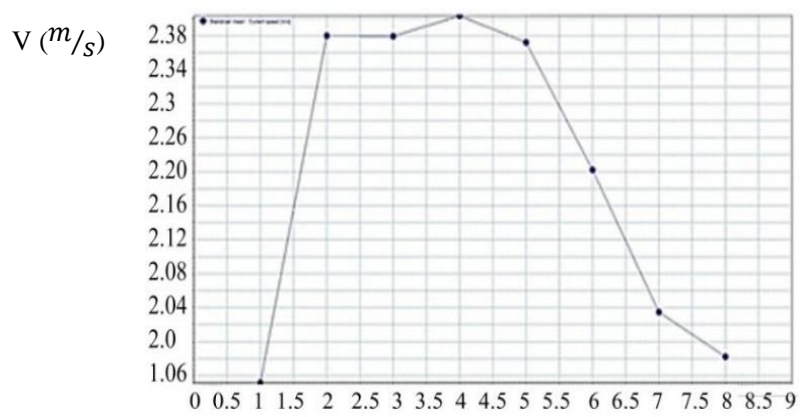

Number of points on cross sections

Fig. 6. Average velocity values in 10 points on third cross section after river training

Based on output data, which result from HEC-RAS, there is one specific value for average velocity in each cross section. The results of two software are compared with each other, so that the average of 10 values in MIKE output should be calculated. Error percentage of the velocity values, computed by MIKE and HEC-RAS in different cross sections of the interval, before and after river training is presented in Fig. 7.

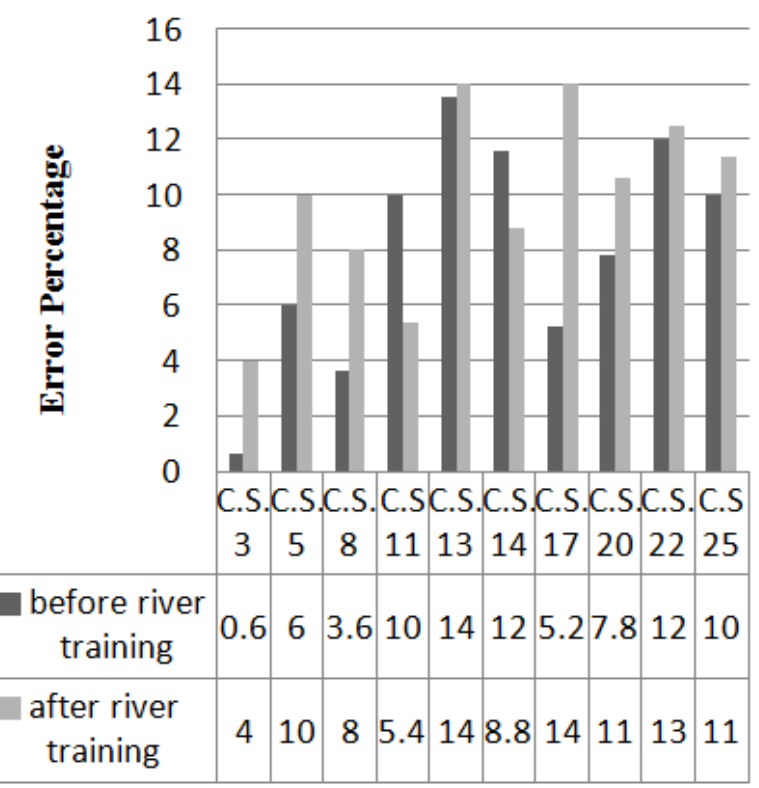

Fig. 7. Error percentage of velocity values between MIKE and HEC-RASS in different cross sections.

According to Fig. 7, error percentage is negligible in comparison between results of two software.

Also the shape of vortexes around the constructed groynes is shown in Fig. 8.

The vortex system averts the main stream to outside of the affected area by groynes, and just one unit of individual vortex expands between groynes. In some cases, the second vortex is appeared inside of affected area. However, the vortex system in all cases doesn't lose its ability of protecting the dike, and main stream lines don't attack the dike straightly. Therefore, the groynes have desired efficiency. Additionally, the flow pattern in the groynes field is not directly affected by the intensity of flow. Regarding to the fact that, the vortex structure in groynes field is a function of the field geometry (length and distance between groynes) and the array of groynes angles, it can be concluded that, the length, distance (twice groynes length), and the right angle for series of groynes is an appropriate status.

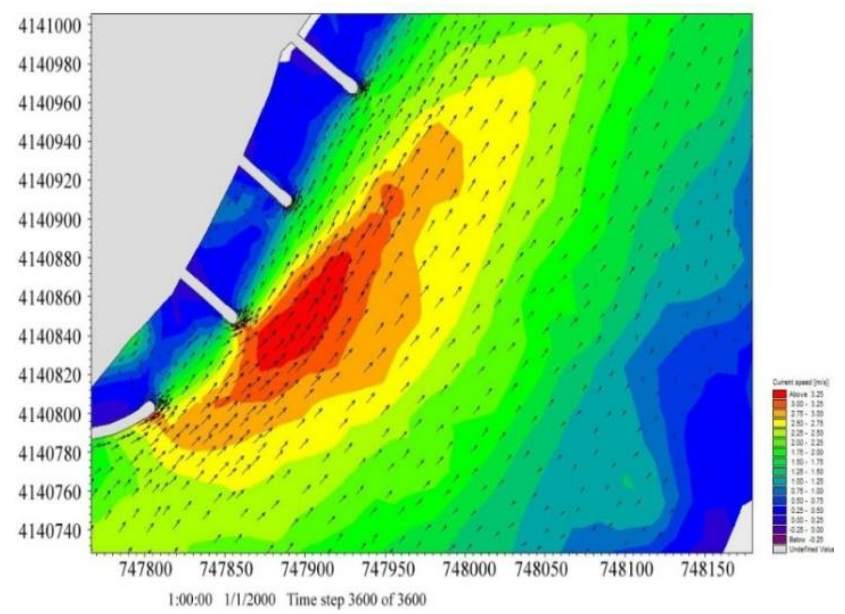

Fig. 8. Velocity vectors and vortexes around the straight groyne

The values of the velocity around the groynes in different shapes were extracted from output data in the format of Time Series and in 4 points for more effective comparison. These points are: (1) Near to headland of groyne, (2) Near to body of groynes, (3) Near to center of vortex (between the center of vortex and the dike of groyne), and (4) Near to longitudinal dike. The location of these points is shown in Fig. 9.

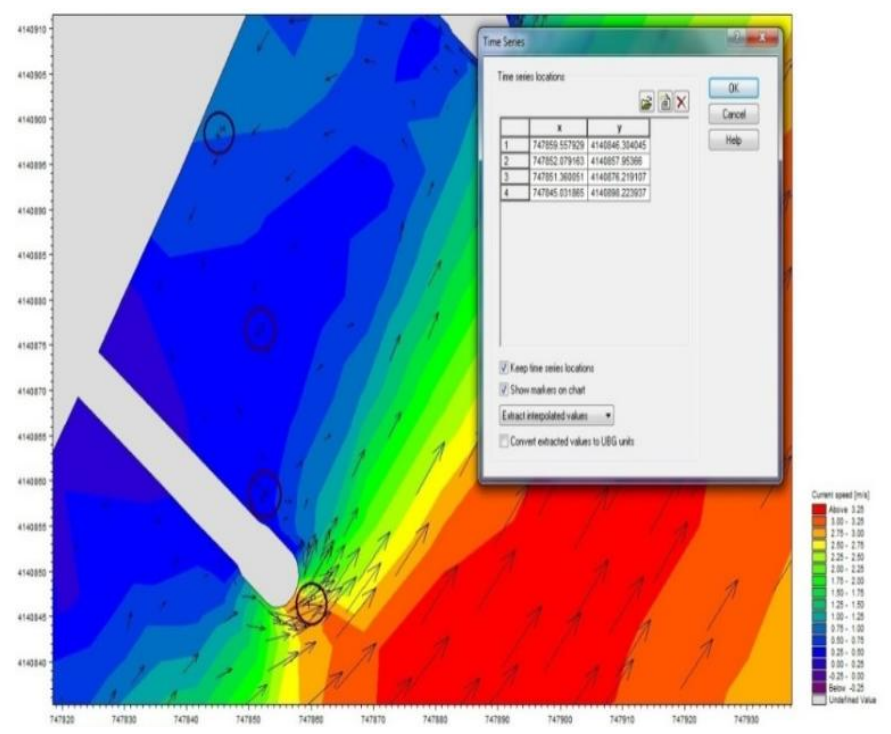

Fig. 9. Location of chosen points around groyne

Velocity values per time in 4 points around the straight groyne, which output from the software are shown in Fig. 10. According to the figures the values of velocity become constant after about 45 minutes and in final time steps. 


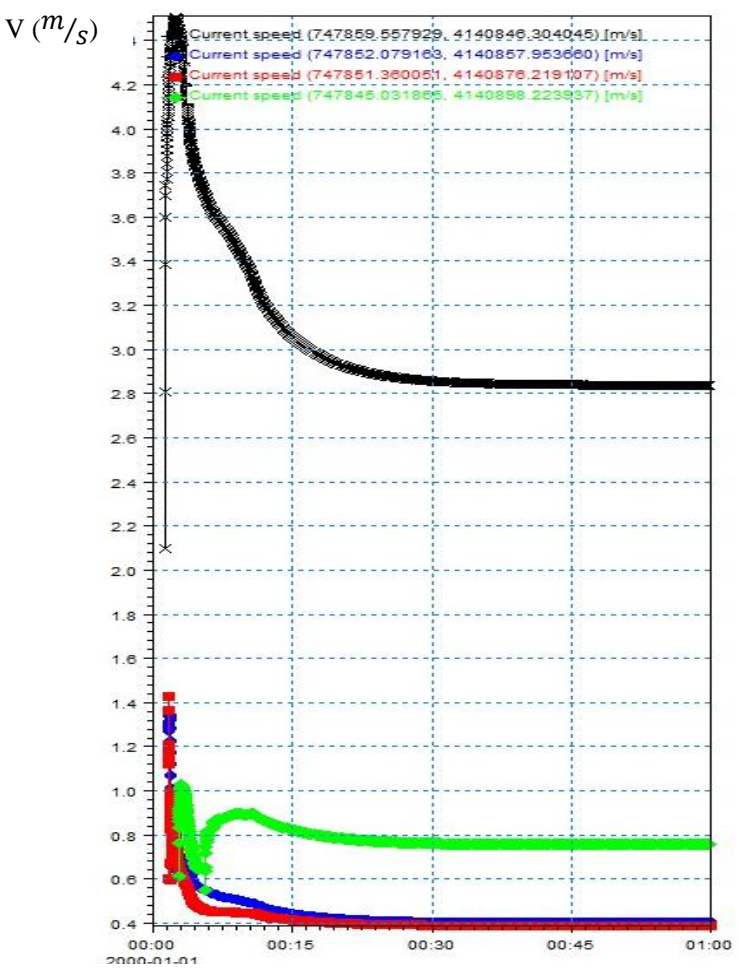

Fig. 10. Velocity values per time in 4 points around the straight groyne.

Also Fig. 11 and Fig. 12 show these values in the same points around L-shape and T-shape groynes separately.

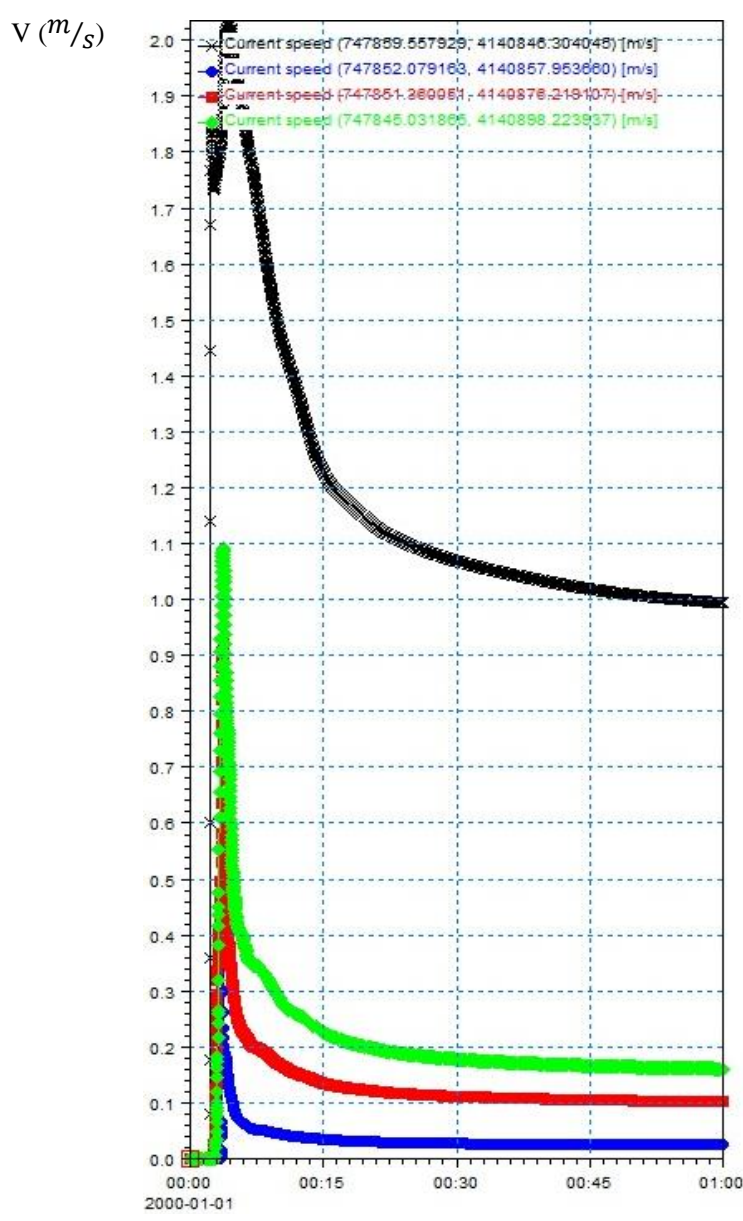

Fig. 11. Velocity values per time in 4 points around the L-shape groyne.

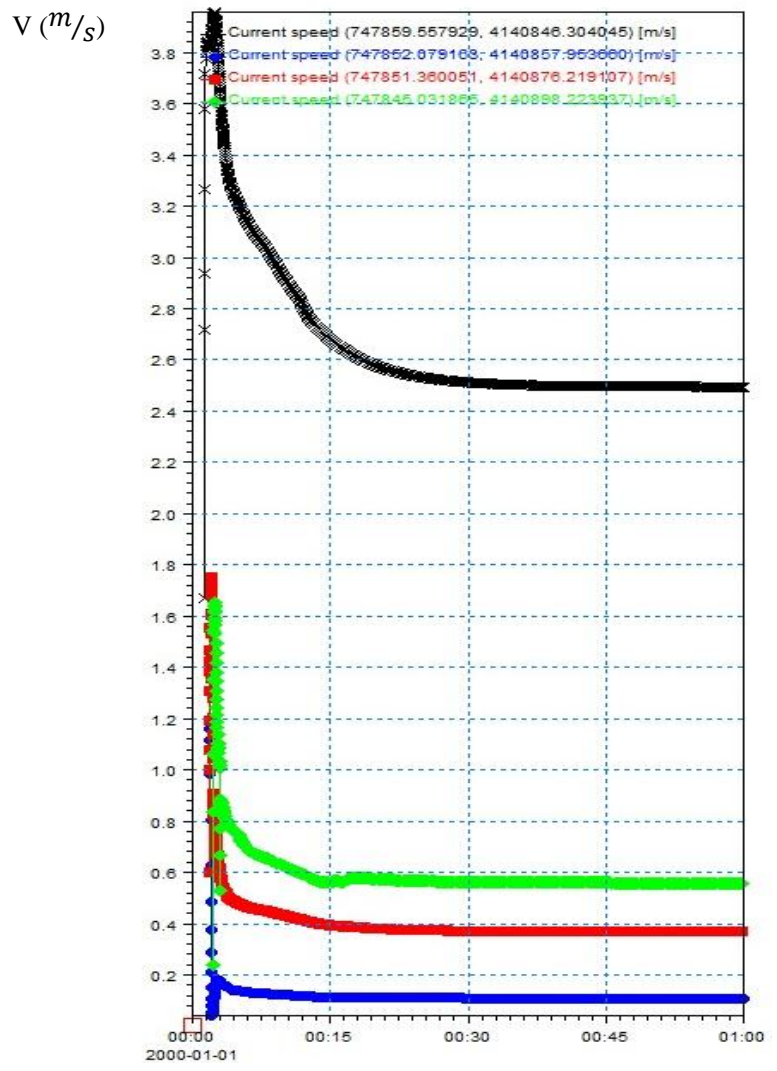

$\mathrm{t}(\mathrm{s})$

Fig. 12. Velocity values per time in 4 points around the T-shape groyne.

Due to comparing the results easily in different shapes of groynes, all of the output data in the final time step (3600 seconds) are presented in Fig. 13.

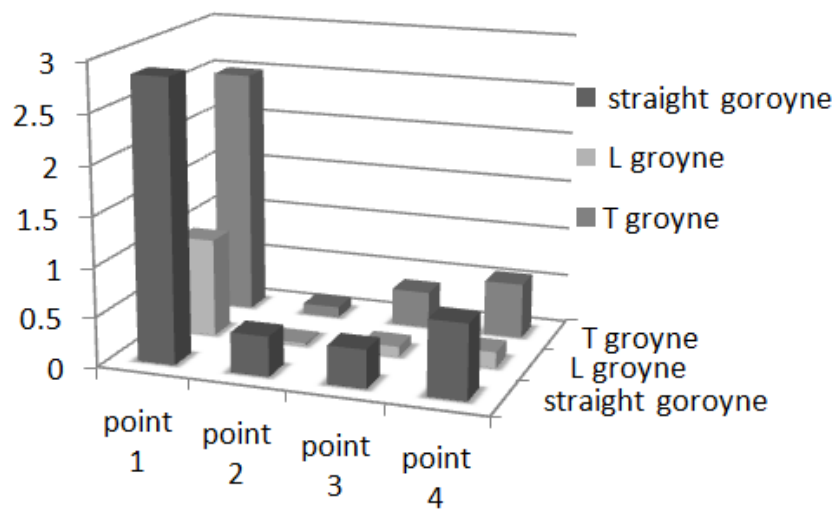

Fig. 13. Velocity values in some points around different shapes of groynes.

According to the figure difference between velocity values around straight groyne and other types of groynes is negligible. For the series of the groynes, because of other considerations such as economical aspect, affordability and speed of implementation and restoration in the river, the constructed form (straight groynes) are more appropriate. However, the shapes of L- shape groynes are more effective for deflecting the flow, and it reduces local scouring in groyne's headland, and references recommend using L shape for the first and final groyne in a series of groynes to improve their efficiency. Therefore it's better to choose L shape for the first and final groyne in the given interval. 


\section{CONCLUSION}

Achachi Area is one of the most vulnerable domains of Ghezel-Ozan River that flood hazards always threaten the area. Therefore, the main purpose of river training scheme is protection of the river lands. Scrutinizing velocity values in different cross sections before and after river training reveals that velocity values at first and last points of the cross section becomes zero after performing the scheme. In conclusion, the groynes and embankment dike are constructed with appropriate height, and they don't allow the stream to enter the adjacent lands of the river. In addition, the velocity after river training has fewer amounts near the longitudinal dike and more amounts in the center of the river. So that it reveals that the groynes have high efficiency, and they are constructed optimally to protect the longitudinal dike and deviate the stream from border to center of the river. Consequently, after constructing the groynes in the given interval, the main channel of the river gets much deeper while sediment settles between the groynes and makes the dikes more stable. The chosen length, spaceing between groynes and their shapes are optimum and the correct forms of vortexes are made between them. However, it's better to replace the first and last groynes in the series of groynes with L-shape groyne.

\section{REFERENCES}

[1] T. Tsujimoto, Y. Toda, H. Furuhata, and H. Shionoya, "Ecological function of series of groins and induced morphology in estuary segment of river with tidal motion - Downstream reach of the Kiso River, Japan," in Proc. 8th Int. Simp. Ecohydraulic, COEX, Seol, Korea.

[2] N. S. Alexander, "Hydrodynamics of groyne fields in a straight river reach: insight from field experiments," Journal of Hydraulic Research, vol. 52, no. 1, pp. 105-120, 2014.

[3] M. F. M. Yousef, "The effect of groyne on river," Literature Review, Delf University, 2002.

[4] P. C. Klingeman, S. M. Kehe, and Y. A. Owusu, "Streambank erosion protection and channel scour manipulation using rockfill dikes and gabions," WRRI-98, Oregon State University, Water Resources Research Institute, Corvallis, Oregon, 1984.

[5] B. Przedwojski, R. Blazejewski, and K. W. Pilarczyk, "River training techniques," Balkema, Rotterdam, The Netherlands, 1995.

[6] H. Omdehghiasi, A. Mojtahedi, and M. A. Lotfollahi-Yaghin, "The comparison of flow characteristics around refraction and right groyne in barotropic and baroclinic conditions," Journal of Marine Science and Application, vol. 14, pp. 376-388, 2015.

[7] A.T. M. Khaleduzzaman, "Experimental study on river course stabilization and restoration by using groin-like structures," Master thesis Kyoto University, Japan, 2004.

[8] W. S. Uijttewaal, "Effects of groyne layout on the flow in groyne fields: Laboratory experiments," Journal of Hydraulic Engineering, vol. 131. no. 9, pp. 782-791, 2005.

[9] M. Ghodsian and M. Vaghefi, "Experimental study on scour and flow field in a scour hole around a T-shape spur dike in a $90^{\circ}$ bend," International Journal of Sediment Research, vol. 24, no. 2, pp. 145$158,2009$.

[10] J. Kang, H. Yeo, C. Kim, "An expe rimental study on a characteristic of flow around groyne area by install conditions," Scientific Research, vol. 4. pp. 636-645, 2012.

[11] J. A. Cunge, F. M. Holly, and A. Verwey, Practical Aspects of Computational River Hydraulics, Pitman press, USA, 1980.

[12] P. Jansen, B. L. Van, M., DeVries, and A., Zanen, Principles of River Engineering, Pitman Press, USA 1979.

[13] M., DeVries, G. J., Klaassen, and N. Struiksma, "On the use of movable bed models for river problems: State of art," Symp. River Sedimentation, Beijing, China, 1989.

[14] Ministry of Energy, Water Resources Management Organization, Office of Executive projects, "The second phase of training GhezelOzan river within the Achachi village area," Final Report, 2007.

[15] MIKE21, Hydrodynamic and Transport Module Scientific Documentation, 2011th edition, Denmark DHI, 2011.

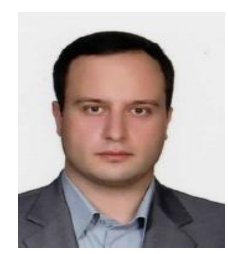

Alireza Mojtahedi was born in 1979. He is working as an assistant professor in the Faculty of Civil Engineering at the University of Tabriz, Iran.

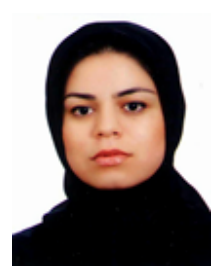

Aida Bagheri Basmenji was born in Tabriz, Iran in 1987. She has earned her M.Sc. degree in the field of water resource engineering of civil engineering from Tabriz University, Iran in 2015.

Her research interests are mathematical modeling and numerical analysis. 